\title{
Law-abiders, lame ducks, and over-stayers: the Africa Executive Term Limits (AETL) dataset
}

\author{
Andrea Cassani ${ }^{1}$ [D
}

Accepted: 1 September 2020 / Published online: 12 October 2020

(C) The Author(s) 2020

\begin{abstract}
Besides elections, the sub-Saharan wave of political reforms of the 1990s led several countries to introduce limits to the number of terms that a chief executive can serve, even though several leaders managed to bypass them. While Africa's executive term limits (ETLs) politics has gained scholarly attention, the literature mostly consists of in-depth small-N analyses. Systematic comparative research is rare. To contribute filling this gap, this article presents a new Africa Executive Term Limits (AETL) dataset. Covering 49 sub-Saharan polities throughout the 1990-2019 period, AETL represents the most complete and updated collection of data on Africa's ETLs politics, and a versatile research tool to address several questions on the present and future of this continent. A preliminary assessment of the new data finds ETLs to be increasingly respected, and to have positive returns for government alternation and development. These findings point to new research avenues that AETL may help travel.
\end{abstract}

Keywords Sub-Saharan Africa · Term limits · Dataset · Democratization · Autocratization $\cdot$ Personal rule

\section{Introduction}

Besides multiparty universal suffrage elections, the dramatic series of regime transitions that Africa experienced during the 1990s led several countries to adopt specific provisions aimed to limit the number of terms that a chief executive can serve. Executive term limits (ETLs) help de-personalise political power and favour

Electronic supplementary material The online version of this article (https://doi.org/10.1057/s4130 4-020-00291-w) contains supplementary material, which is available to authorized users.

Andrea Cassani

andrea.cassani@unimi.it

1 Department of Social and Political Science, Università degli Studi di Milano, Via

Conservatorio, 7, 20122 Milan, Italy 
alternation at the government (Maltz 2007). For this reason, their introduction in African reformed constitutions was welcomed as an important step in the process of institutionalisation that decades of post-colonial neopatrimonialism and "big man" rule have delayed (Akech 2011; Cheeseman 2018). Unfortunately, the global wave of (re-)autocratization that has been unfolding since the late 1990s (Luehrmann and Lindberg 2019; Cassani and Tomini 2020) had no mercy on the region. ETLs have thus become one of the main targets of African would-be autocrats that aim to hang on to power and revive personal rule, often successfully.

Africa's ETLs politics has been at the centre of a lively debate during the past two decades, especially concerning leaders' decision to either comply or challenge these legal restrictions (Baker 2002; Reyntjens 2020; to name a few). However, this literature mostly consists of qualitative small-N studies, and the generalisability of their findings has rarely been assessed (but see Baturo 2014 and McKie 2019 for cross-regional analyses). Moreover, several other comparative questions remain unanswered, regarding the broader consequences ETLs could have on political and developmental outcomes. Likewise, the African experience with ETLs has been contrasted with the experience of other regions in very few occasions (Baturo and Elgie 2019).

To address the relative shortage of systematic comparative research on Africa's ETLs politics, this article introduces the Africa Executive Term Limits dataset (AETL), which covers the 1990-2019 period and 49 sub-Saharan countries. Organised in three different levels of analysis (i.e. countries, leaders, terms), AETL is the most complete, updated and versatile collection of data on Africa's ETLs politics, offering a new tool for the comparative study of African politics and the investigation of a plurality of research questions.

The article proceeds as follows. The first section illustrates the importance of studying ETLs politics in contemporary Africa. The second section describes the dataset's structure. The remaining of the article is devoted to demonstrating the usefulness of the new dataset to study African politics. More specifically, the third section maps trends and patterns of ETLs compliance and manipulation. The fourth section investigates the political and developmental consequences of ETLs politics. The preliminary analyses presented in this article find ETLs to be increasingly respected, and to have positive returns for government alternation and development. The final section briefly discusses these findings, which highlight avenues for future research that could be explored thanks to the new AETL dataset.

\section{The importance of (studying) executive term limits in Africa}

In a continent plagued by decades of post-colonial "big man" politics (Jackson and Rosberg 1982), the African wave of democratic reforms of the 1990s (Bratton and van de Walle 1997) led constitution-makers to adopt specific mechanisms to deter the personalisation of political power, that is, the overlapping between office and office-holder. Accordingly, besides elections, universal suffrage and multipartyism, many African countries introduced limits to the number of terms that a chief executive can serve (Baturo 2019). 
Executive term limits (ETLs) may take different forms (Corrales and Penfold 2014). They can either prescribe a total ban on re-election, permit only nonconsecutive re-election, or establish a fixed number of mandates that a person is allowed to serve as chief executive (either continuously or in total). Regardless of what these constitutional provisions specifically prescribe, ETLs address the same problem. As legal pre-commitments to consider alternative candidates (Ginsburg et al. 2011), ETLs impede prolonged tenures and put the precept of executive rotation into effects (Venice Commission 2018). Moreover, while in principle ETLs could merely produce succession between leaders from the same party, in practice ETLs increase opposition's chances of victory, thus favouring government alternation (Maltz 2007; Cheeseman 2010), with positive returns for the legitimacy of democracy and state institutions (Bratton 2004; Moehler and Lindberg 2009).

However, ETLs democratic qualities remain ambiguous. First, as a ban on a leader's possibility to run for re-election, ETLs also limit voter freedom to choose the preferred candidate (Venice Commission 2018). Second, ETLs are compatible with authoritarianism (Lebas 2016). Indeed, they remove a key mechanism of accountability, which may lead non-re-electable presidents to indulge in predatory behaviours (Prempeh 2008; Morse 2018). Moreover, alternation at the government is neither necessary nor sufficient to democracy. Opposition leaders could turn as authoritarian as their predecessors, or even more (Wahman 2014).

Even the broader (i.e. non-strictly political) consequences of ETLs remain contested. On one hand, ETLs could be beneficial for development through the production of government turnover and the influx of fresh ideas (Carbone and Pellegata 2020). On the other hand, ETLs may induce a "lame duck" syndrome that hampers policy-making during an incumbent's last term in office. More generally, ETLs could deprive the nation of uniquely skilful leaders, leaving their development programmes unaccomplished and squandering the experience they have accumulated while in office (Maltz 2007).

The restriction to voters' freedom of choice and the possible negative implications of government alternation for development are among the arguments that several contemporary African leaders have employed to challenge ETLs. While ETLs' pro-democratization effects are disputed, the manipulation of ETLs less ambiguously produces (re-)autocratization. Manipulating ETLs often requires the loosening of the checks and balances to the executive power, and similarly often it taints competition in future elections (Cassani and Tomini 2020).

Given its relevance for the future of democracy and development in this region, Africa's ETLs politics has gained attention. Scholars examined the interests behind both the institutionalisation of ETLs (McKie 2017) and their subsequent manipulation (Posner and Young 2007, 2018). Concerning the latter, both the strategies implemented (Tull and Simons 2017) and the factors either easing or obstructing their success have been studied (Dulani 2011; Harkness 2017; Reyntjens 2016, 2020). Questions such as whether and how ETLs shape African presidents' policy decisions have received less attention, though, which is surprising given the role of leaders and leadership changes for Africa's development (Carbone and Pellegata 2020). 
It should be noticed that this literature mostly consists in qualitative studies (recent examples include Heilbrunn 2019; VonDoepp 2019; Cheeseman 2019; Heyl 2019; Moestrup 2019). Medium/large-N regional analyses are rare and often descriptive. While studying in-depth a single or few cases is key to our understanding of ETLs politics, statistical comparative analysis is similarly important to capture broader trends and to assess the strength of the relationships that qualitative methods bring to light. However, sound medium/large- $\mathrm{N}$ comparative analysis requires methodically collected and codified information. Currently, the available information lacks either the coverage or the kind of detail that are necessary.

\section{The Africa Executive Term Limits dataset}

The Africa Executive Term Limits (AETL) offers a new tool to study African politics and to compensate for the relative shortage of comparative analysis in this research field. Covering 49 sub-Saharan countries observed from 1990 to 2019, it aims to represent the most complete and detailed collection of data about ETLs politics south of the Sahara. AETL differs from any existing source of such data in four main interrelated respects, namely, the geographical coverage, the amount of codified information, the detail of this information, and its organisation.

Currently, detailed information on ETLs in sub-Saharan Africa is only available for relatively few countries that have been studied in-depth. In most cases, regionallevel analyses classify either countries or leaders based on a limited number of criteria (e.g. ETLs introduction, compliance and manipulation). AETL brings together, crosschecks, updates, develops and complements the information that can be drawn from the literature, by relying on both primary sources and other existing political science datasets (i.e. Constitute Project; Archigos; Varieties of Democracy; Database of Political Institutions; Africa Leadership Change; UCDP/PRIO Armed Conflict Dataset).

The structure is another key advantage distinguishing AETL. AETL organises the heterogeneous amount of information it gathers in three levels of analysis that are ordered hierarchically as follows: country, leader, term. In practice, AETL three-level structure corresponds to as many smaller sub-datasets that can be easily merged thanks to country, leader and term unit identifiers. Each dataset contains both information on ETLs politics and on several of its correlates. While a full list of the new variables that AETL contains is available in the codebook, this section illustrates the dataset's structure.

Countries represent AETL's most general level of analysis. AETL provides information about 49 sub-Saharan states regarding independence, colonial legacy, ethnic fractionalisation, the form of government, the year of the electoral transition, the regional organisation(s) to which they belong, civil war periods and coups d'état. Concerning ETLs politics, this sub-dataset records term length, whether and when a country has introduced ETLs, what ETLs specifically prescribe, and the relevant constitutional changes occurred since their adoption.

Besides a country's characteristics and overall ETLs record, students of African politics may want to look at and compare the ETLs performance of each leader, 
which could vary significantly both between leaders of different countries and between leaders from the same country. Hence, leaders represent AETL's second level of analysis. More specifically, this sub-dataset focuses on 212 different individuals that served as chief executive in the 49 sub-Saharan states between 1990 and 2019 , even if only for a few days in some cases.

To be sure, some of these leaders never went through an election. Some leaders seized power through force (e.g. Johnny Paul Koroma in Sierra Leone); others served as interim rulers (e.g. Catherine Samba-Panza in Central African Republic). Moreover, some leaders took office multiple times, and sometimes in different ways. ${ }^{1}$ AETL accounts for this variance and describes the career of each observed leader. Besides indicators of birth and gender, AETL specifies whether a given leader is or was a military officer, whether he/she already served as chief executive before the country's electoral transition, and how many times he/she took power ever since. For each post-transition power seizure, moreover, AETL reports a leader's entry and exit dates and modalities. Concerning ETLs politics, AETL records the following leader-level information: the number of terms served as an elected president; the term length; whether a leader is term-limited; the specific type of ETLs; how many times (and when) a leader dealt with ETLs while in office, and what he/she did in these occasions.

For researchers specifically interested in the various trajectories that Africa's ETLs politics has taken during the past three decades, AETL offers a third subdataset that focuses on 129 African leaders that were elected at least one time since 1990, including those leaders who came to power by other means but were subsequently legitimised via elections. However, differently from the previous sub-dataset, in this case the units of observation are leaders' terms, that is, the spells of time starting with the election of a given leader and ending with the subsequent election (or re-election) — or earlier if an incumbent is overthrown, resigns or dies. Hence, as an example, a leader that serves two terms appears twice in AETL term-level subdataset, which contains 251 observations, overall.

Besides information on the timing and mode in which each observed term starts and ends, AETL term-level sub-dataset informs about the existence and the type of ETLs, whether it is a leader's first, second or subsequent term, whether a leader dealt with ETLs during this term and whether he/she respected or manipulated ETLs. Most importantly, for every manipulation attempt, AETL records whether the bid was successful or failed and how the manipulation was pursued-that is, the content of the proposed constitutional change, the institutional channels through which a leader tried to pass the amendment, and the intervention of other veto-players (e.g. the military; protesters).

\footnotetext{
1 For example, the former president of Gambia Yahya Jammeh took power in a 1994 coup and was subsequently elected in 1996. Similarly, Nigerian Goodluck Jonathan took power in 2010 as interim president following the death of his predecessor and was subsequently elected in 2011.
} 


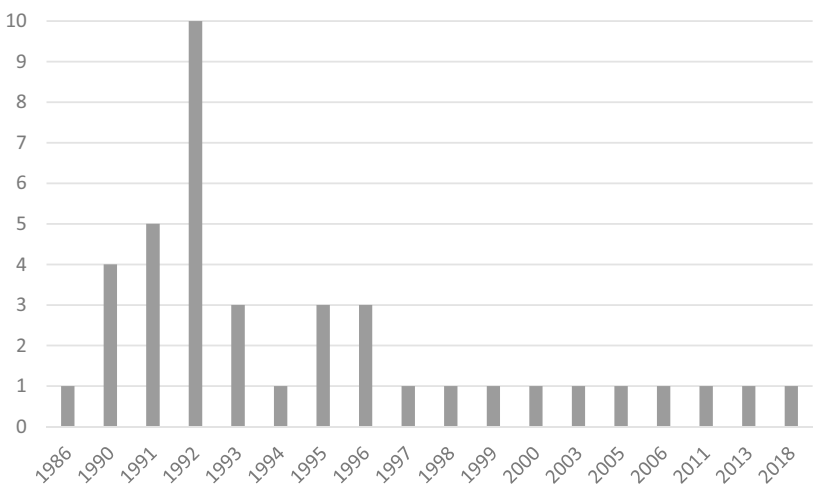

Fig. 1 ETL introduction in sub-Saharan Africa. Source: AETL. Notes: Each column records the number of countries that adopted ETL in the corresponding year

\section{Trajectories of ETLs politics in sub-Saharan Africa}

The attitudes that contemporary African leaders have maintained towards ETLs represent one of the most debated issues in sub-Saharan politics. Given the prevalence of qualitative research, AETL offers a new tool to assess the generalisability of the findings regarding the determinants of ETLs compliance and manipulation that we could draw from the in-depth study of a single or few cases. ${ }^{2}$ While hypothesis testing is beyond the scope of this article, this section uses AETL to set the ground for conducting this kind of research by mapping compliance and manipulation trends.

The easiest way to track the diffusion of ETLs in the African continent during the third wave of democratization is to rely on AETL country-level dataset. As Fig. 1 shows, 40 out of 49 sub-Saharan states have adopted these constitutional provisions, thus far. The majority of them did so during the first part of the 1990s, the "pioneer" being Liberia in 1986. The delayed introduction of ETLs in other countries is often explained by a history of civil conflict and military coups during the 1990s (e.g. Rwanda, Democratic Republic of Congo). Virtually all the African polities that adopted ETLs have a presidential or semi-presidential form of government. Botswana and South Africa, which are characterised by a parliamentary system with an indirectly elected executive presidency, are the exceptions.

Concerning the type of ETLs, 71\% of sub-Saharan constitutions prescribe that a president cannot serve more than two mandates overall. Among them, the constitution of Botswana fixes a maximum of 10 years in office, reflecting the parliamentary nature of the government and the 5-year length of a legislature. The constitutions of Equatorial Guinea, Guinea-Bissau, Mozambique and São Tomé and Príncipe

\footnotetext{
2 These include a past as non-elected ruler (Heilbrunn 2019 on Togo), the precedent set by the predecessors (Posner and Young 2018 and Cheeseman 2019 on Kenya), military loyalty (Harkness 2017 on Cameroon), ruling party cohesion (VonDoepp 2019 on Malawi), opposition strength (Cheeseman 2019 on Zambia) and civil society's mobilisation capacity (Moestrup 2019 on Burkina Faso; Heyl 2019 on Senegal).
} 


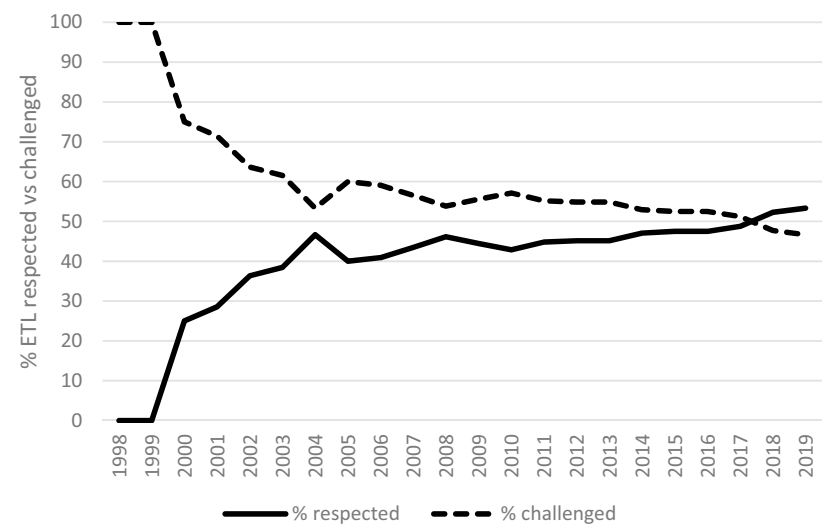

Fig. 2 African presidents' ETL compliance rate. Source: AETL. Notes: The solid and dashed lines measure the cumulative share of cases in which African presidents respected and challenged ETL, respectively

establish a two-term limit but explicitly envisage the possibility for a leader to run for further non-consecutive terms, after having stepped down. Seychelles had a three-term limit until 2017, whereas Comoros was characterised by a rotating presidency (every 4 years) between the three main islands until 2018.

The nine sub-Saharan countries without ETLs include four non-electoral regimes (Eritrea, eSwatini, Somalia, South Sudan), three parliamentary systems (Ethiopia, Lesotho, Mauritius) and Cape Verde, a semi-presidential system in which executive power rests on the Prime Minister. In practice, Gambia represents the region's only presidential system that has not yet adopted ETLs.

As anticipated, the institutionalisation of ETLs by no means represented a point of arrival for sub-Saharan countries. The decision of an incumbent to abide by the rules of the game and step down in due time, or challenge ETLs and try to overstay in office, has become one of the main crossroads driving the political development of sub-Saharan new electoral regimes. To map how African presidents have addressed this dilemma, thus far, we could focus on AETL leader-level dataset and the 103 term-limited presidents that ruled in sub-Saharan Africa between 1990 and 2019.

Among them, 61 leaders have never reached ETLs. Excluding leaders that were still in office at the end of 2019, the explanations of early terminations include coups d'état (e.g. Marc Ravalomanana in Madagascar), resignation (e.g. Thabo Mbeki in South Africa), natural death (e.g. Umaru Musa Yar'Adua in Nigeria), retirement (e.g. Jose Eduardo Dos Santos in Angola), and electoral defeat (e.g. John Mahama in Ghana).

Focussing on the 42 African presidents from 31 countries that completed the legally allowed executive mandates and dealt with ETLs, what did they choose to do? Figure 2 shows that the regional record of ETLs compliance is mixed. Africa's ETLs politics livened up at the end of the 1990s, and the debut was inauspicious. The first three leaders that reached ETLs_-Blaise Compaoré (Burkina Faso), Abdou Diouf (Senegal), and Sam Nujoma (Namibia)—obtained permission to run for 
another term. More generally, Fig. 2 suggests that African leaders have been more likely to challenge ETLs than to step down voluntarily, until recently. Since 2010, the trend seems to have reversed, though. Between 2010 and 2019, 18 African leaders reached the end of their final term in office. Two-thirds of them (i.e. 12 out 18) abided by the rules and stepped down. In 2018, for the first time in Africa's electoral history, law-abiders have surpassed over-stayers, cumulatively.

Incumbent leaders who refuse to step down when the end of their final term in office is approaching face a second dilemma regarding how to bypass ETLs. AETL term-level sub-dataset offers a tripartite classification of sub-Saharan ETLs manipulation strategies (cf. Baturo 2019). In a majority of cases (62\%), African presidents pursued the removal of ETLs from the constitutions of their countries (e.g. Paul Biya in Cameroon). Alternatively, aspiring over-stayers could seek an extension of ETLs, for instance through the institutionalisation of a longer ETLs clause (e.g. Denis Sassou Nguesso in the Republic of the Congo) or the introduction of an additional ad hoc term (e.g. Sam Nujoma in Namibia). Finally, elusion is typically pursued through a constitutional change that does not modify an existing ETLs clause but resets the countdown, thus discarding the mandates already served based on the non-retroactivity of the reform (e.g. Abdoulaye Wade in Senegal).

Besides manipulation strategies, AETL considers the potential veto-players an aspiring over-stayer may encounter. These actors include the constitutional court, the national assembly, the civil society, and the military. The national assembly is the actor that has been most frequently involved in these reform processes $(71 \%)$, typically to vote a constitutional amendment. Citizens took part in $38 \%$ of ETLs manipulation attempts, as voters in a constitutional referendum (e.g. Rwanda), but also as protesters in street demonstrations (e.g. Burkina Faso). In turn, the constitutional court has been formally consulted only in five cases to rule over ETLs disputes. ${ }^{3}$ Military interventions are even more exceptional. Only in three cases, the army staged a coup against a president seeking to hold on to power illegally (e.g. Niger).

What happened when ETLs have been challenged in sub-Saharan Africa? Overall, African presidents managed to hang on to power in two-thirds of the cases, whereas seven attempts failed. Figure 3 analyses the effectiveness of the strategies of ETLs manipulation implemented and of the veto-players encountered. First, it is interesting to note that, while it represents African presidents' preferred strategy, the outright removal of ETLs also is the riskiest option, that is, the one with the lowest success rate. Both eluding and extending ETLs appear safer strategies for a leader wishing to hold on to power, probably because they are less disruptive of the existing order.

Concerning veto-players' ability to stop ETLs manipulation attempts in sub-Saharan Africa, the most evident finding is their weakness. The parliament has rarely

\footnotetext{
3 To be sure, despite their formally legal nature, ETLs-related court rulings, parliamentary bills and referenda largely represent "autocratic legalism" (Scheppele 2018), concealing a great deal of court cooptation, legislative vote buying, and biased electoral procedures.
} 


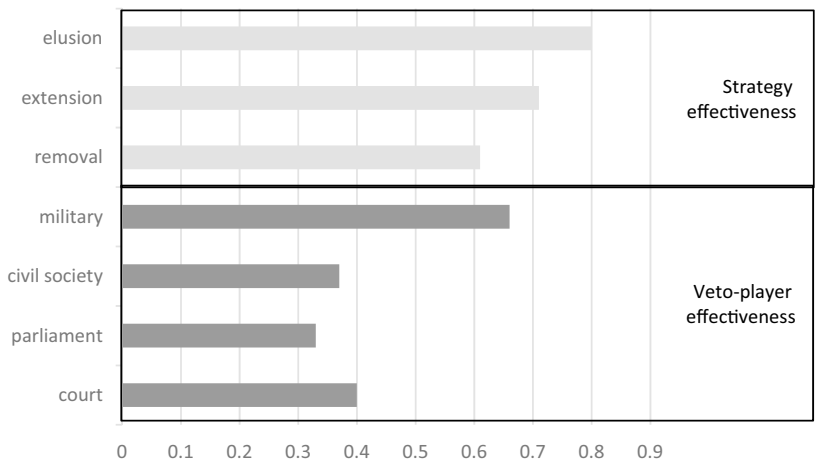

Fig. 3 ETL manipulation strategies and veto-players: success and failure. Source: AETL. Notes: The upper panel reports the success rate of the different ETL manipulation strategies, to measure their effectiveness. In turn, the lower panel reports the failure rate of ETL manipulation attempts when different veto-players intervened, as a measure of their ability to stop an aspiring over-stayer

opposed a constitutional amendment regarding the modification or removal of ETLs efficiently. Courts and citizens do not display significantly better performances, unfortunately. Not surprisingly, the army emerges as the most effective veto-players, in the few cases in which it actually intervened.

\section{The political and developmental consequences of ETLs}

Besides the benefits AETL could bring to the comparative analysis of Africa's ETLs politics and of the continent's processes of democratization and autocratization, the new dataset can help address a plurality of research questions. To highlight a few other prospective applications, and to show how easily AETL could be combined with other existing datasets, we may reconsider the willingness of several African presidents to engage in hazardous manoeuvres aimed to manipulate ETLs in light of the political and economic implications of these institutions. Without entering these debates, this section presents a preliminary test of a few arguments that have been advanced but rarely analysed systematically.

Concerning political outcomes, ETLs are said to favour alternation at the government between candidates from different parties. Ruling parties' performance is poorer when they run elections with a new candidate, which cannot count on the socalled "incumbency advantage" (Maltz 2007; Cheeseman 2010). The incumbency advantage stems from a president's control over the political agenda and the public budget, the patronage network that he/she administrates, a better media exposure, and voters' preference for the "evil they know" (Ginsburg et al. 2011). By removing the incumbency advantage, ETLs should indirectly raise opposition's chances to win.

To offer an empirical demonstration of ETLs alternation effect, Table 1 summarises the outcomes of 145 presidential elections held between 1990 and 2019 in sub-Saharan Africa, based on the presence of the incumbent in the candidates' 
Table 1 ETL and electoral outcomes. Source: AETL and Africa Leadership Change Dataset (Carbone and Pellegata 2020)

\begin{tabular}{lllcr}
\hline & Confirmation & Succession & Alternation & Total \\
\hline Incumbent standing & & & & \\
2nd term & 63 & - & 10 & 73 \\
3rd + term & 36 & - & 3 & 39 \\
Open-seat & & 11 & 12 & 23 \\
Term limit & - & 10 & 0 & 10 \\
Other & - & 21 & 25 & 145 \\
Total & 99 & & & \\
\hline
\end{tabular}

Cells report the raw numbers of elections. Elections in parliamentary systems, founding elections, post-coup elections, and elections in Comoros until 2018 (that is, until the rotating presidency mechanism was in place) are not considered

list. Concerning elections in which the incumbent stood, the table specifies whether the incumbent run for a second or subsequent term. These elections could result in either confirmation or alternation. Concerning open-seat elections, the table specifies whether the incumbent did not stand because of term limits or due to other reasons-such as natural death, retirement or resignation. These latter elections could result in either succession (i.e. a candidate from the incumbent's party wins) or alternation.

Sitting presidents were confirmed in $68 \%$ of all examined elections and in $88 \%$ of the 112 elections they run. An incumbency advantage does exist. However, opposition electoral performance changes dramatically if we shift attention to open-seat polls not contested by the incumbent. While ruling party's successor candidates remain favoured overall, opponents won $52 \%$ of the 23 votes that ETLs made openseat, which confirms ETLs alternation effect. A closer look at the data suggests that the strength of this effect is decreasing over time, though. During the first two decades of electoral politics (1990-2009), we count 11 opposition victories, $63 \%$ of which were favoured by ETLs. During the past decade (2010-2019), opposition candidates defeated ruling parties 14 times, and only $35 \%$ of these cases occurred in elections that the incumbent did not contest because of ETLs.

ETLs do not only shape political outcomes. Two popular arguments among ETLs detractors-especially, African aspiring over-stayers-point to the negative consequences of these institutions on development. On one hand, by forcing executive turnover, ETLs may deprive a nation of uniquely skilful and experienced leaders, whose medium/long-term development programmes risk remaining unaccomplished (Maltz 2007). On the other hand, ETLs could induce a "lame duck" syndrome that hampers policy-making during the final term of an incumbent.

As an exploratory analysis of the ETLs-development nexus, Fig. 4 plots the average growth rates achieved by African elected leaders during their first, second, and subsequent terms. Two main findings could be highlighted. First, if we compare African presidents' economic performance during the first and second term in office, no evidence of a "lame duck" effect can be detected. Yet the most interesting result emerges from the comparison between African presidents' 


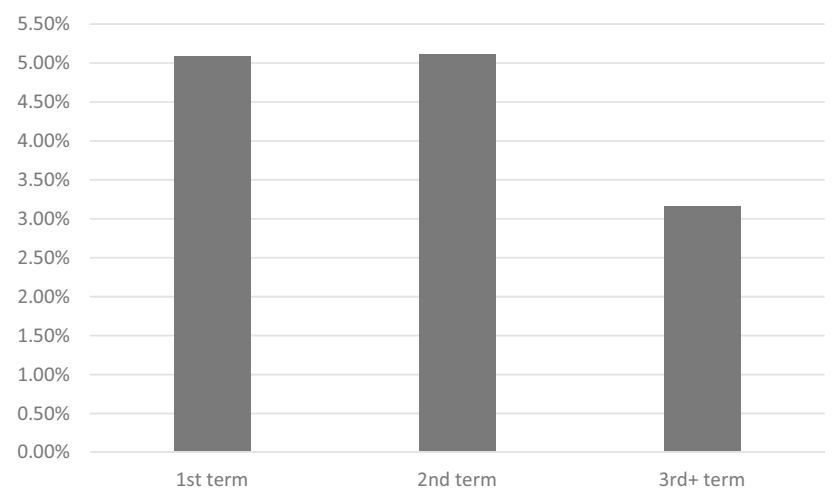

Fig. 4 ETL and economic growth. Source: AETL and World Bank's World Development Indicators. Notes: leaders elected in parliamentary systems are not considered, with the exception of Botswana and South Africa's term-limited presidents

developmental performance during the first two terms and during third and subsequent terms. In this case, the graph highlights a substantial gap in terms of growth rates, which suggests a negative effect of prolonged tenures.

\section{Conclusion}

The introduction of ETLs in several sub-Saharan states has significantly shaped politics in this region during the past three decades. Despite the relevance of these institutions for Africa's present and future and the attention they have gained in the academic debate, a shortage of systematic and comprehensive collections of data has hampered comparative research, thus far.

This article illustrated a new AETL dataset, which aims at filling this gap. The geographical coverage, and the detailed and large amount of information that AETL codifies and organises in three nested levels of analysis, are the main advantages of this dataset. Besides its use as an updated and comprehensive source of information on ETLs politics south of the Sahara, the dataset helps investigate a plurality of comparative questions regarding, for instance, the incentives behind ETLs compliance and defiance, the determinants of success and failure in ETLs manipulation, and the broader policy-making consequences of ETLs.

To set the ground for future research, the article presented a few explorative analyses using the new data. Preliminary findings highlight a negative influence of prolonged tenures for development, a positive effect of ETLs on government alternation (even though opposition parties appear more and more able to challenge incumbent rulers, and not only their successor candidates), and an increasing trend in African leaders' compliance with ETLs. Taken together, this is good news for Africa, but a more thorough assessment of this evidence is required. 


\section{The new AETL dataset represents a versatile research tool to conduct this kind of research.}

Open Access This article is licensed under a Creative Commons Attribution 4.0 International License, which permits use, sharing, adaptation, distribution and reproduction in any medium or format, as long as you give appropriate credit to the original author(s) and the source, provide a link to the Creative Commons licence, and indicate if changes were made. The images or other third party material in this article are included in the article's Creative Commons licence, unless indicated otherwise in a credit line to the material. If material is not included in the article's Creative Commons licence and your intended use is not permitted by statutory regulation or exceeds the permitted use, you will need to obtain permission directly from the copyright holder. To view a copy of this licence, visit http://creativecommons.org/licen ses/by/4.0/.

\section{References}

Akech, M. 2011. Constraining government power in Africa. Journal of Democracy 22 (1): 96-106.

Baker, B. 2002. Outstaying one's welcome: The presidential third-term debate in Africa. Contemporary Politics 8 (4): 285-301.

Baturo, A. 2014. Democracy, Dictatorship, and Term Limits. Ann Arbor: The University of Michigan Press.

Baturo, A. 2019. Continuismo in comparison: Avoidance, extension and removal of presidential term limits. In The Politics of Presidential Term Limits, ed. A. Baturo and R. Elgie, 75-99. Oxford: Oxford University Press.

Baturo, A., and R. Elgie. 2019. The Politics of Presidential Term Limits. Oxford: Oxford University Press. Bratton, M. 2004. The alternation effect in Africa. Journal of Democracy 15 (4): 147-158.

Bratton, M., and N. van de Walle. 1997. Democratic Experiments in Africa: Regime Transitions in Comparative Perspective. Cambridge: Cambridge University Press.

Carbone, G., and A. Pellegata. 2020. Political Leadership in Africa: Leaders and Development South of the Sahara. Cambridge: Cambridge University Press.

Cassani, A., and L. Tomini. 2020. Reversing waves and concepts: From democratization to autocratization. European Political Science 19 (2): 272-287.

Cheeseman, N. 2010. African elections as vehicles for change. Journal of Democracy 21 (4): 139-153.

Cheeseman, N. 2018. Introduction: Understanding African politics: Bringing the state back in. In Institutions and Democracy in Africa, ed. N. Cheeseman, 1-38. Cambridge: Cambridge University Press.

Cheeseman, N. 2019. Should I stay or should I go? Term-limits, elections, and political change in Kenya, Uganda and Zambia. In The Politics of Presidential Term Limits, ed. A. Baturo and R. Elgie, 311337. Oxford: Oxford University Press.

Corrales, J., and M. Penfold. 2014. Manipulating term limits in Latin America. Journal of Democracy 25 (4): $157-168$.

Dulani, B. 2011. Personal Rule and Presidential Term Limits in Africa. Ph.D. dissertation, Michigan State University.

Ginsburg, T., J. Melton, and Z. Elkins. 2011. On the evasion of term limits. William \& Mary Law Review 52 (6): 1807-1892.

Harkness, K. 2017. Military loyalty and the failure of democratization in Africa: How ethnic armies shape the capacity of presidents to defy term limits. Democratization 24 (5): 801-818.

Heilbrunn, J. 2019. Presidential term limits in Togo: Electoral accountability postponed. In The Politics of Presidential Term Limits, ed. A. Baturo and R. Elgie, 199-219. Oxford: Oxford University Press.

Heyl, C. 2019. Senegal (1970-2016): Presidential term limit reforms never come alone. In The Politics of Presidential Term Limits, ed. A. Baturo and R. Elgie, 339-361. Oxford: Oxford University Press.

Jackson, R., and C. Rosberg. 1982. Personal Rule in Black Africa: Prince, Autocrat, Prophet, Tyrant. Berkeley, LA: University of California Press.

LeBas, A. 2016. Term limits and beyond: Africa's democratic hurdles. Current History 115: 169-174. 
Luehrmann, A., and S. Lindberg. 2019. A third wave of autocratization is here: what is new about it? Democratization 26 (7): 1095-1113.

Maltz, G. 2007. The case for presidential term limits. Journal of Democracy 18 (1): 128-142.

McKie, K. 2017. The politics of institutional choice across sub-Saharan Africa: Presidential term limits. Studies in Comparative International Development 52 (4): 436-456.

McKie, K. 2019. Presidential term limit contravention: Abolish, extend, fail, or respect? Comparative Political Studies 52 (10): 1500-1534.

Moehler, D., and S. Lindberg. 2009. Narrowing the legitimacy gap: Turnovers as a cause of democratic consolidation. Journal of Politics 71 (4): 1448-1466.

Moestrup, S. 2019. Presidential term limits in Burkina Faso. In The Politics of Presidential Term Limits, ed. A. Baturo and R. Elgie, 363-383. Oxford: Oxford University Press.

Morse, J. 2018. Presidential power and democratization by elections in Africa. Democratization 25 (4): 709-727.

Posner, D., and D. Young. 2007. The institutionalization of political power in Africa. Journal of Democracy 18 (3): 126-140.

Posner, D., and D. Young. 2018. Term limits: Leadership, political competition, and the transfer of power. In Institutions and Democracy in Africa, ed. N. Cheeseman, 260-277.

Prempeh, H. 2008. Presidents untamed. Journal of Democracy 19 (2): 109-123.

Reyntjens, F. 2016. A new look at the evidence. Journal of Democracy 27 (3): 61-68.

Reyntjens, F. 2020. Respecting and circumventing presidential term limits in sub-Saharan Africa: A comparative survey. African Affairs 119 (475): 275-295.

Scheppele, K. 2018. Autocratic legalism. University of Chicago Law Review 85 (2): 545-583.

Tull, D., and C. Simons. 2017. The institutionalisation of power revisited: Presidential term limits in Africa. Africa Spectrum 52 (2): 79-102.

Venice Commission. 2018. Report on Term Limits. Council of Europe Study No. 908/2017: 1-25.

VonDoepp, P. 2019. The politics of presidential term limits in Malawi. In The Politics of Presidential Term Limits, ed. A. Baturo and R. Elgie, 291-309. Oxford: Oxford University Press.

Wahman, M. 2014. Democratization and electoral turnover in sub-Saharan Africa and beyond. Democratization 21 (2): 220-243.

Publisher's Note Springer Nature remains neutral with regard to jurisdictional claims in published maps and institutional affiliations.

Andrea Cassani is Research Fellow at the Department of Social and Political Sciences of the Università degli Studi di Milano, in Italy. His research mainly focuses on democratization and autocratization. 